\title{
Synthesis and Characterization of Homo and Mixed Ligand Complexes of Fe(III) with Hydroxypyridinone and Hydroxypyranone Type Ligands
}

\author{
Kanwal Zahid ${ }^{\mathrm{a} *}$, Shazia Nisar ${ }^{\mathrm{a}}$, Saima Imad ${ }^{\mathrm{b}}$, Shazia Perveen ${ }^{\mathrm{c}}$, \\ Shazia Ghaffar ${ }^{a}$ and Nasreen Fatima ${ }^{a}$ \\ ${ }^{a}$ Department of Chemistry, University of Karachi, Karachi-75270, Pakistan \\ ${ }^{\mathrm{b}}$ Chemical Metrology Division, National Physical and Standards Laboratory (PCSIR), Islamabad, Pakistan \\ ${ }^{c}$ Department of Chemistry, NED University of Engineering and Technology, Karachi-75270, Pakistan
}

(received March 28, 2019; revised June 9, 2019; accepted June 17, 2019)

\begin{abstract}
Hydroxypyridinone and hydroxypyranone are known to be used for the treatment of iron overload by chelation therapy for a long time. Both the ligands have their own side effects when used as medicines. In the present study homo and mixed ligand complexes of both the ligands with iron were prepared and characterized by UV-visible spectrophotometry, Potentiometric study, IR spectroscopy, SEM/EDX and XRD. Overlay spectra obtained from UV-visible spectroscopy of our studied system show the formation of different types of species and confirm that mixed ligand complex is different from the other two systems. Potentiometric titration curves of homo and mixed ligand complexes show the formation of different types of species at different $\mathrm{pH}$ and confirm the formation of mixed ligand complex. The comparative results of SEM images of these systems show different surface topologies and hence conform to the formation of mixed ligand complex.
\end{abstract}

Keywords: mixed ligand complexes, iron, hydroxypyridinone, hydroxypyranone, chelation therapy

\section{Introduction}

Chelation therapy is required for the treatment of diseases associated with iron overload in the body (Santos and Chaves, 2015). The existing clinical use of Iron chelators are subcutaneous or intravenous, oral deferiprone and deferasirox (Ragab et al., 2013). Compounds of hydroxypyridinone family have been used for chelation therapy, as a possible candidate of iron chelators (Saghaie and Hider, 2008). A bidentate chelator that belongs to one of its class 3-hydroxy 4-pyridinone is, deferiprone, also known as $\mathrm{Cp} 20$.

Deferiprone (DFP), (3-hydroxy-1,2-dimethyl-4(1H)pyridone) was proved to be first oral iron chelator for iron overload chelation therapy in 1999 in Europe (Jamuar and Lai, 2012).

To overcome the iron overload, that could be a result of routine lifesaving blood transfusion process required for thalassemic, this drug have proven to change their lives from bad to good (Galanello and Origa, 2010). Other than hydroxypyridinone there is a closely resembled family of compounds known as hydroxypyranone (Burgess and Rangel, 2008). Members of later family have also been studied by researchers for their *Author for correspondence; E-mail: skrj1929@gmail.com strong influence in metal chelation. Maltol (3-hydroxy2-methyl-4H-pyran-4-one and kojic acid (KA), (5hydroxy-2-(hydroxymethyl)-4H-pyran-4-one) are the two famous individuals of this family. However, in this paper we have focused on the previously less considered area of research i.e., the study of mixed ligand complexes of hydroxypyridinone and hydroxypyranone. Synthesis and characterization of mixed ligand complex of iron, Kojic acid and deferiprone along with their respective homo-ligand complexes was investigated using different spectral techniques. Out of our three, studied system of complexes, structural characterization of the two difficult to crystallize complexes (in terms of their single crystals) was achieved by IR spectroscopy and SEM/EDX analysis. Though, one of the homo-ligand component system iron-deferiprone complex was successfully characterized through other techniques.

\section{Materials and Methods}

All the chemicals used were of analytical grade and were used without further purification. Source of $\mathrm{Fe}^{\text {(III) }}$ was $\mathrm{FeCl}_{3} \cdot 6 \mathrm{H}_{2} \mathrm{O}$. High purity Deferiprone and Kojic acid were purchased. For UV/Visible spectral analysis the complex solutions were prepared by following the scheme, given in Table 1. 
Table 1. Preparation of mixed ligand and their individual complexes for UV/visible spectral analysis

\begin{tabular}{|c|c|c|}
\hline \multicolumn{3}{|c|}{ Mixing ratio for mixed ligand complexes } \\
\hline $\mathrm{Fe}^{(\mathrm{III})}$ & KA & DFP \\
\hline 1 & 1 & 1 \\
\hline 1 & 2 & 1 \\
\hline 1 & 3 & 1 \\
\hline 1 & 1 & 2 \\
\hline \multicolumn{3}{|c|}{ Mixing ratio for two individual complexes } \\
\hline 1 & 1 & 0 \\
\hline 1 & 2 & 0 \\
\hline 1 & 3 & 0 \\
\hline 1 & 0 & 1 \\
\hline 1 & 0 & 2 \\
\hline 1 & 0 & 3 \\
\hline
\end{tabular}

The spectra were recorded using DU-730 UV/Vis spectrophotometer. IR spectra in the range of 4000 to $400 \mathrm{~cm}^{-1}$ were collected through Shimadzu IR Prestige 21. For combined SEM/EDX analysis the SEM/EDX made of JEOL, Japan, with SEM model JSM-6380A and EDX detector model EX-54175jMU were used. Single crystal XRD (Single crystal X-ray diffraction Bruker Smart Apex) was employed for the structural determination of iron-deferiprone crystal. Throughout the experiment, $\mathrm{pH}$ was maintained by acetate buffer system using $\mathrm{pH}$ meter, Ohaus, Starter 2100. Same pH meter was used for the potentiometric study.

For the synthesis of $\mathrm{Fe}(\mathrm{DFP})_{3}$, a series of solution of complex was prepared by appropriate addition of three and greater equivalents of DFP, (3-hydroxy-1,2dimethyl-4(1H)-pyridone) from its buffered stock solution to $1 \mathrm{mmol}$ equivalent of $\mathrm{FeCl}_{3} \cdot 6 \mathrm{H}_{2} \mathrm{O}$. $\mathrm{pH} 4.0$ was maintained in each $10.0 \mathrm{~mL}$ flask by acetate buffer. Reaction between ligand and metal yielded a reddish marron solution. Later solutions were stored in cold at $4{ }^{\circ} \mathrm{C}$. Shiny crystals were appeared in solutions in good yield, about after a month. Suitable crystals were then subjected to single crystal X-ray analysis.

In this study from equimolar, $2.5 \times 10^{-3} \mathrm{M}$ stock solution of $\mathrm{Fe}^{(\mathrm{III})}$, KA and DFP, appropriate aliquot solution of desired component was taken in $10 \mathrm{~cm}^{3}$ volumetric flask, to prepare $2.5 \times 10^{-4} \mathrm{M}$ complexes of the following $\mathrm{L} / \mathrm{M}$ ratio and later volume of each flask was made upto the mark with acetate buffer of $\mathrm{pH} 4.0$

For the synthesis of $\mathrm{Fe}(\mathrm{KA})_{3}$, to $10.0 \mathrm{~mL}$ water solution of kojic acid (1.119 g, $7.88 \mathrm{mmol})$, the $10.0 \mathrm{~mL}$ water solution of $\mathrm{FeCl}_{3} .6 \mathrm{H}_{2} \mathrm{O}(0.6709 \mathrm{~g}, 2.485 \mathrm{~m} / \mathrm{mol})$ was added, followed by addition of $\mathrm{NaOH}(0.32 \mathrm{~g}, 8 \mathrm{mmol})$ to same complex solution. After stirring for about $3 \mathrm{~h}$ at room temperature the mixture was made solvent free by suction filtration method. The dark reddish marron residue was dissolved in ethanol-water mixture of 1:1 ratio (Nurchi et al., 2010).

Synthesis of mixed ligand complex. To synthesize mixed ligand complex, a hot methanolic $(10.0 \mathrm{~mL})$ solution of $\mathrm{Fe}^{(\mathrm{III})}$ was mixed with $(1 \mathrm{mmol})$ of kojic acid, (5-hydroxy-2-(hydroxymethyl)-4H-pyran-4-one) and (1 mmol) of deferiprone, (3-hydroxy-1,2-dimethyl$4(1 \mathrm{H})$-pyridone). The $\mathrm{pH}$ of mixture was adjusted to 4.0 by addition of acetate buffer. The mixture was kept under reflux for about three hours, no precipitate formation was observed. After refluxing, this mixture was left to cool that later was transformed to a thick, shiny, oily material.

However, several attempts to obtain fine, shiny, needle like crystals were made by dissolving and recrystallizing through solvents of varying polarity. All these attempts resulted in the same type of oily complex. Hence the complex in the same state was subjected to further analysis.

\section{Results and Discussion}

UV-Visible spectroscopic studies. The absorption spectroscopic method is considered as a reliable method for detection of mixed ligand complex in solution.

Comparative spectral studies of the individual complexes to that of their mixed ligand complex in terms of change in their absorbance intensities were done. The metal concentration was kept the same in all the studied systems, presence of isosbestic points in spectra, minor shifting and differences in absorption intensities of the peaks helped us to interpret the spectra of the three systems. The overlay spectra of the complexes as two individual and one mixed ligand complex system show the formation of different type of species, (Fig. 1).

The absorption spectra of mixed ligand complex are different from the other two systems. With similar concentration of $\mathrm{Fe}^{\text {(III) }}(0.25 \mathrm{mmol})$ in all the complexes the observed absorption intensities pattern was $\mathrm{Fe}^{(\mathrm{III})}$ DFP complex $>$ mixed ligand complexes (of all combination ratios) $>\mathrm{Fe}^{(\mathrm{III})} \mathrm{KA}$ complex. Spectra of mixed ligand complex formed by different combining ratios of two ligands with metal, have shown some isosbestic points in between their spectra and the intersecting 


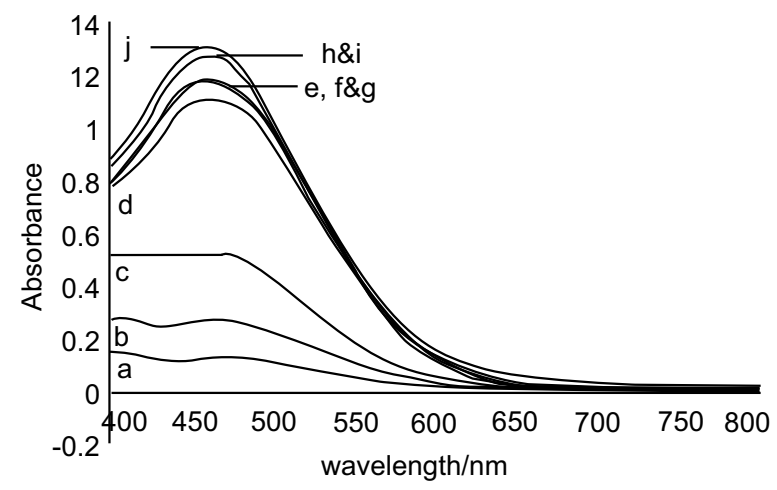

Fig. 1. Overlay spectra of $\mathrm{Fe}^{(\mathrm{III})}$ with kojic acid (KA) and deferiprone(DFP) as their individual and mixed ligand type complexes in different combining molar ratios, where, $\mathrm{a}=\mathrm{Fe}: \mathrm{KA}:$ DFP $(1: 1: 0) ; \mathrm{b}=$ Fe:KA:DFP $(1: 2: 0) ; \mathrm{c}=$ Fe:KA:DFP $(1: 3: 0) ; \mathrm{d}=(1: 2: 1)$; e, f \& $g=$ Fe:KA:DFP $(1: 3: 1),(1: 1: 1)$; $h \& i=F e: K A: D F P(1: 0: 1,1: 0: 2)$ and $j=$ Fe:KA:DFP $(1: 0: 3)$.

points are also present in the spectra of two individual complexes and mixed ligand complex. Based on the spectral observations we assume that in solution the mixed ligand complexes with general formula $\mathrm{ML}_{1} \mathrm{~L}_{2} \cdot \mathrm{nH}_{2} \mathrm{O}, \mathrm{M}\left(\mathrm{L}_{1}\right)_{2} \mathrm{~L}_{2}$ or $\mathrm{ML}_{1}\left(\mathrm{~L}_{2}\right)_{2}$ might be present where:

$\mathrm{M}=\mathrm{Fe}^{(\mathrm{IIII})} ; \mathrm{L}_{1}=\mathrm{KA}$, and $\mathrm{L}_{2}=\mathrm{DFP}$.

The mole ratio plot has shown 1:3 stoichiometry for $\mathrm{Fe}^{\text {(III) }}$ complex with kojic acid deferiprone at $\mathrm{pH} 4.0$ (Fig. 2-3), respectively. Previously reported spectral studies indicate that there also exists another species of complex with 1:2 stoichiometry. However, the specie distribution diagram shows 1:2 M:L complex species is negligible or very low at this $\mathrm{pH}$ (Nurchi et al., 2010; Nurchi et al., 2008). These points of species distribution support our study of mixed ligand complex.

Potentiometric studies. The potentiometric titration curves were used to study different behaviour of the both, homo and mixed ligand complexes over all $\mathrm{pH}$ ranges.

These titrations were performed with standardized $\mathrm{NaOH}$ solution and the data was plotted as $\mathrm{pH}$ change for incremental addition of standardized $\mathrm{NaOH}$.

Titration of homo-ligand complexes, $\mathrm{Fe}^{(\mathrm{IIII})}$-Kojic acid (Fe-KA), $\mathrm{Fe}^{(\mathrm{III})}$-deferiprone (Fe-DFP) and mixed ligand complex of $\mathrm{Fe}^{(\mathrm{III})}$-Kojic acid -deferiprone (Fe-KA-DFP) in 1:1:1 metal to ligands ratio was performed (Fig. 4).

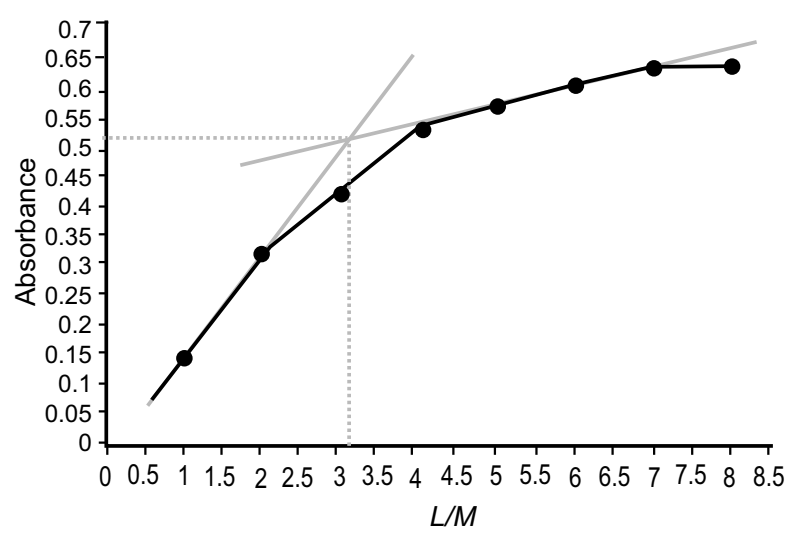

Fig. 2. Mole ratio plot of $\mathrm{Fe}^{(\mathrm{III})-K o j i c}$ Acid complex at $465 \mathrm{~nm}$.

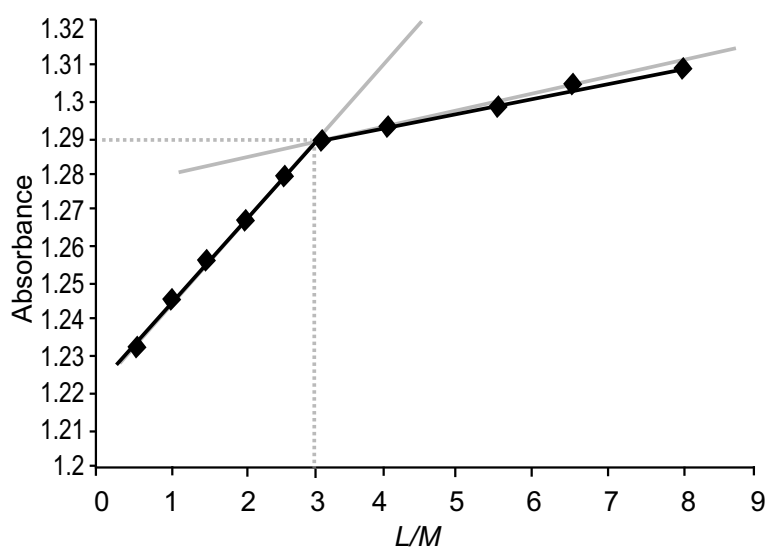

Fig. 3. Mole ratio plot of $\mathrm{Fe}^{(\mathrm{III})}$-deferiprone complex at $460 \mathrm{~nm}$.

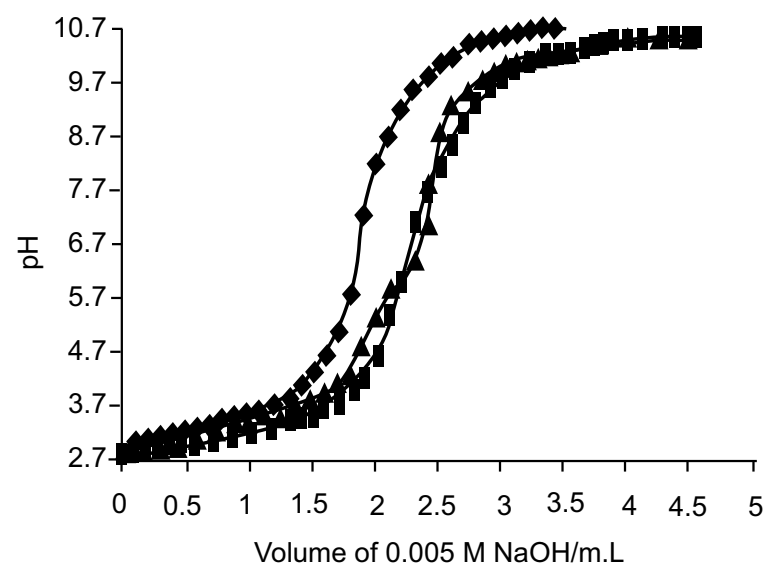

FKD111 -FeKA11 \FeDFP11

Fig. 4. Potentiometric titration plot of homo and mixed ligand complexes. 
Potentiometric titration curve of $\mathrm{Fe}^{(\mathrm{III})}-\mathrm{KA}$ showed that complex formation between metal and ligand is possible at wide $\mathrm{pH}$ range, but at varying $\mathrm{pH}$ different species with different stability might occur. The ML specie is present at very low $\mathrm{pH}$, in the range 2-3. The specie, most probably $\mathrm{ML}_{2}$ may exist from $\mathrm{pH} 3$ to 6 and the specie $\mathrm{ML}_{3}$ might be present at higher $\mathrm{pH}$ between $\mathrm{pH}$ 6-8. Potentiometric titration curve is supporting the formation of three types of species.

Titration curve of $\mathrm{Fe}^{(\mathrm{III})}$-DFP is showing very sharp curves between $\mathrm{pH}$ 3-8. Specie with ML stoichiometry is expected to exist in very low concentration between $\mathrm{pH}$ 2-3. The $\mathrm{ML}_{2}$ and $\mathrm{ML}_{3}$ species are present in good concentration between $\mathrm{pH}$ 3-4 and 5-8, respectively. The titration curve of mixed ligand complex is showing the formation of one specie in high concentration between the $\mathrm{pH}$ 3-8.

Infra-red spectroscopy. FTIR spectroscopic studies of metal carbonyl compounds normally show distinct change mainly in $(\mathrm{C}=\mathrm{O})$ frequency upon complex formation (Piantavini et al., 2017).

In the systems investigated here, all complexes have shown characteristic peaks belonging to the stretching vibrations of carbonyl group in the range 1645-1647 $\mathrm{cm}^{-1}$ that originally were present at higher frequencies in the free ligands. A bathochromic shift for stretching frequency of $(\mathrm{C}=\mathrm{C})$, the assigned frequencies to the double bond inside the heterocyclic aromatic ring was observed in the range of 1400 to $1600 \mathrm{~cm}^{-1}$ (Fig. 5).

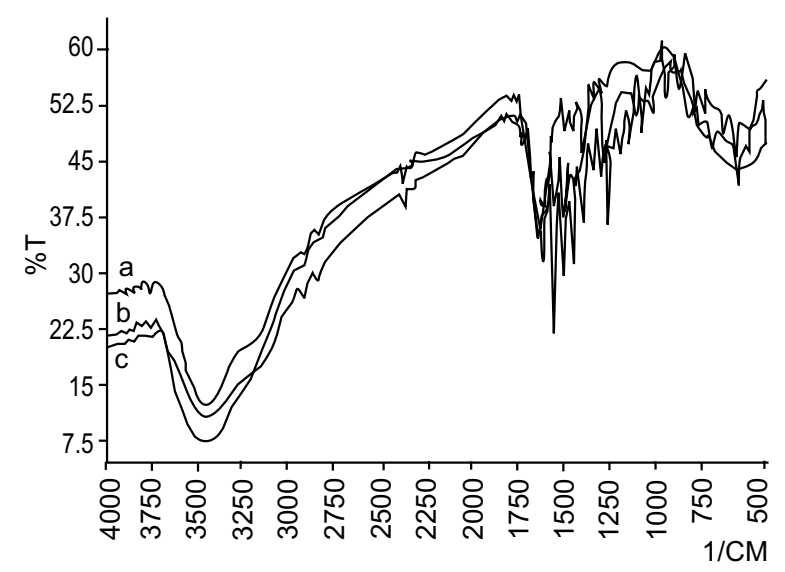

Fig. 5. Overlay IR spectra of (a) $\mathrm{Fe}^{(\mathrm{III}) \text {-Deferiprone }}$ (b) $\mathrm{Fe}^{\text {(III) }}$ with kojic acid and deferiprone and (c) $\mathrm{Fe}^{(\mathrm{III})}-\mathrm{Kojic}$ acid.
Thus, the above comparative view of the ligand and complexes about the characteristic peak shifting are indicative of the fact that metal chelation has been through the carbonyl and hydroxyl groups of the ligand. The interaction of $(-\mathrm{OH})$ enolic group with the $\mathrm{Fe}^{(\mathrm{III})}$ during the formation of complexes has also been proved by the disappearing of the broader $(-\mathrm{OH})$ band in complexes that were present at $3149 \mathrm{~cm}^{-1}$ in DFP and $3174 \mathrm{~cm}^{-1}$ in KA. The broad band in part c of Fig. 8, i.e, Fe-KA complex at $3441-3446 \mathrm{~cm}^{-1}$ is due to presence of primary alcohol $-\mathrm{OH}$ of $\left(\mathrm{CH}_{2} \mathrm{OH}\right)$. The similar band is evident in other metal complexes of Kojic acid (Piantavini et al., 2017). Similarly, the in-bend frequencies of $(-\mathrm{OH})$ enolic groups have also shifted to higher values in metal complexes. Moreover, presence of broad band in the spectrum of other two complexes are attributed to asymmetric stretching vibration of $\mathrm{H}_{2} \mathrm{O}$, with their corresponding bending vibrations in the region $1650-1700 \mathrm{~cm}^{-1}$. Water molecules are evident from $\mathrm{X}$-ray structure of $\mathrm{Fe}^{(\mathrm{III})}$-DFP complex. This broad band along with its corresponding bending vibration giving the clue for the presence of water molecule in the structure of other complex too. Moreover, the M-O stretching frequency, for all types of complexes was observed in the range of $490-570 \mathrm{~cm}^{-1}$.

It is to be noted that $(-\mathrm{OH})$ from primary alcohol $\left(-\mathrm{CH}_{2} \mathrm{OH}\right)$ in $\mathrm{KA}$ has a peak assignment at $1070 \mathrm{~cm}^{-1}$ that remains unchanged in $\mathrm{Fe}^{(\mathrm{III})}$-kojic acid complex hence, explaining its non-participating behaviour towards complex formation. A peak of weak intensity at 1066 $\mathrm{cm}^{-1}$ in mixed ligand complex is a clue that complex is of hetero-ligand in nature.

SEM/EDX studies. The comparative results of SEM images are also confirming different surface topology of mixed ligand complex than that of the two other studied systems. The SEM image for mixed ligand complex (Fig. 6C), is much more compact than the other two complexes (Fig. 6A-B). It was observed that growth of this compound is much more refined as compared to the growth seen for other two compounds and hence, it might be inferred as being due to a new mixed ligand complex.

As far as elemental analysis is concerned for the three systems elemental environment in term of their mass $\%$ closely matched (Table 2). The mass $\%$ sum of the three elements is not equals to $100 \%$ because of the presence of some other elements in little mass $\%$. These elements have come from the matrix in which synthesis and analysis was done, as $\mathrm{Cu}$ was $1.75 \%$ in $\mathrm{Fe}(\mathrm{DFP})_{3}$, in 

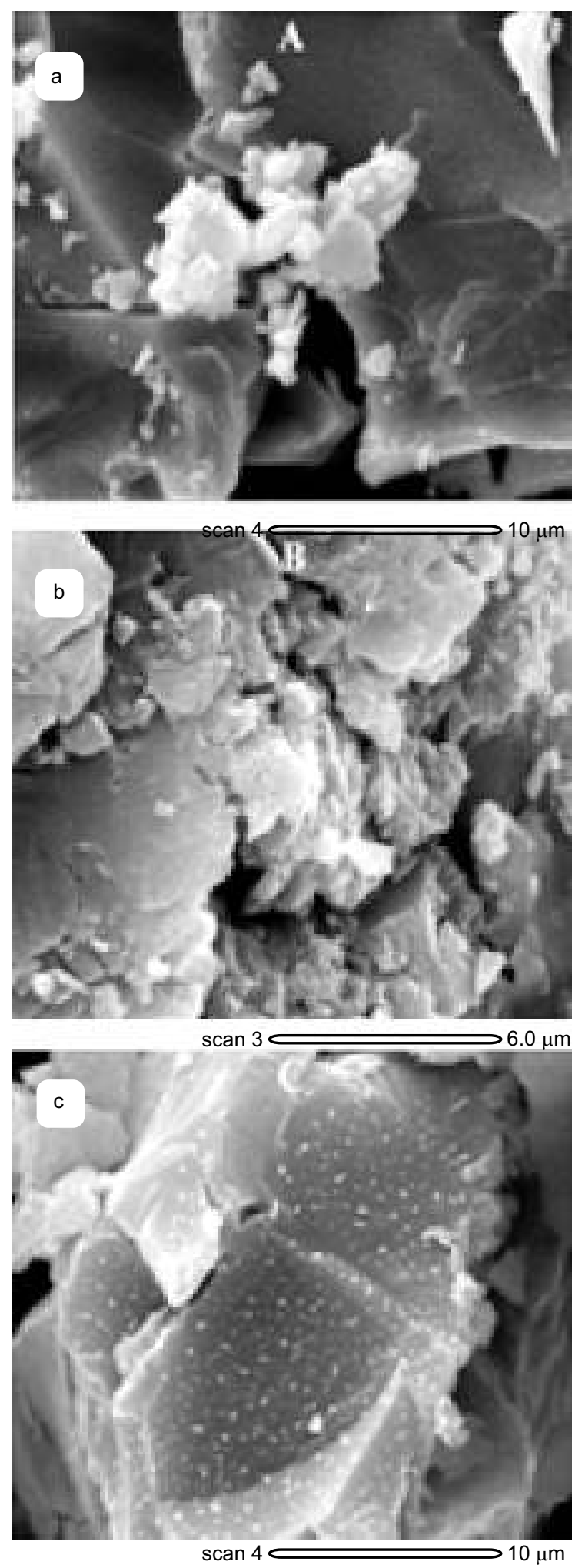

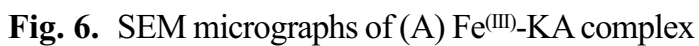
(B) $\mathrm{Fe}^{(\mathrm{III})}$-DFP complex (C) $\mathrm{Fe}^{(\mathrm{III})}$-mixed ligand complex with 5,000 times magnification power. other two complexes presence of $\mathrm{Cu}, \mathrm{Zn}, \mathrm{Na}, \mathrm{Cl}$ was detected. $\mathrm{Na}$ and $\mathrm{Cl}$ would have come from the acetate buffer system used to maintain $\mathrm{pH} 4.0$ whose ionic strength was adjusted to $0.1 \mathrm{M}$ by adding $\mathrm{NaCl}$.

\section{Single crystal diffraction of $\mathrm{Fe}^{(\mathrm{III})}$-deferiprone crystal.}

Table 2. Mass $\%$ of the elements of the three complexes obtained through SEM/EDX analysis

\begin{tabular}{llll}
\hline \hline Elements & $\mathrm{Fe}(\mathrm{KA})_{3}$ & $\mathrm{Fe}(\mathrm{DFP})_{3}$ & $\begin{array}{l}\text { Mixed ligand } \\
\text { complex }\end{array}$ \\
\hline $\mathrm{C}$ & 36.36 & 59.80 & 51.02 \\
$\mathrm{O}$ & 32.72 & 25.80 & 28.86 \\
$\mathrm{Fe}$ & 26.95 & 12.65 & 9.46 \\
Total & 96.03 & 98.25 & 89.34 \\
\hline \hline
\end{tabular}

Single crystal XRD for iron deferiprone (Fig. 7) revealed that in the $\mathrm{Fe}(\mathrm{DFP})_{3} .8 \mathrm{H}_{2} \mathrm{O}$, the $\mathrm{Fe}^{(\mathrm{III})}$ ion is six coordinate complex containing $\mathrm{Fe}^{\text {(III) }}$ core in monoclinic system, space group P3 with $\mathrm{a}=\mathrm{b}=16.6928 \AA, \alpha=6.8655 \AA$ with $\alpha=90^{\circ}, \beta=90^{\circ}, \gamma=120^{\circ}$ further solved parameters for the crystal structure are; volume, $\mathrm{V}=16.568$ (3) $\AA^{3}, \mathrm{z}=3$ calculated density $=1.433 \mathrm{~g} / \mathrm{cm}^{3}$. Moreover, the structure was refined by full-matrix least-squares on $\mathrm{F}^{2} \cdot \mathrm{R}=4.3 \%$ (5687 reflection collected).

The previously reported crystal structure of the $\mathrm{Fe}(\mathrm{DFP})_{3}$ also have P3 space group (Charalambous et al., 1988). However, our findings were different in following terms:

- Presence of eight, water of crystallization instead of twelve.

- Differences were found not only in M-O bond length but also in carbon to carbon and carbon to nitrogen bond length of the ring.

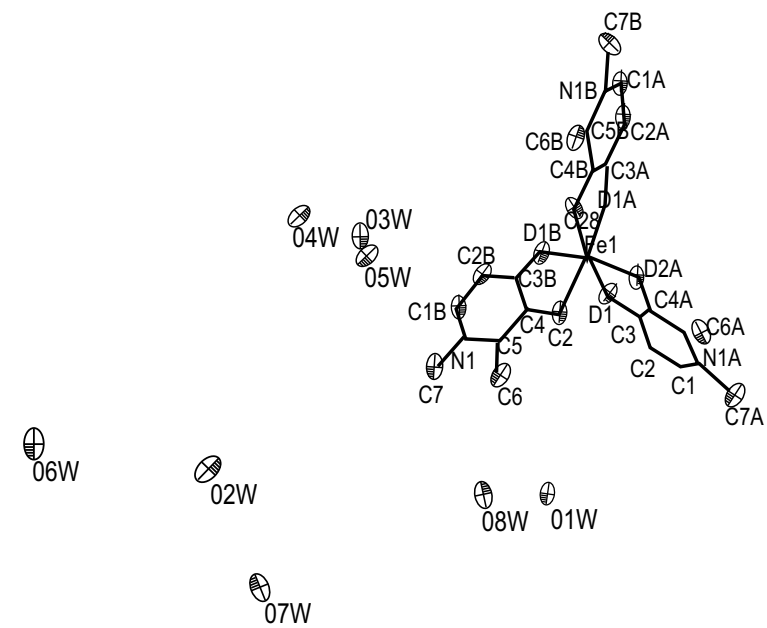

Fig. 7. The structure of $\mathrm{Fe}(\mathrm{DFP})_{3} .8 \mathrm{H}_{2} \mathrm{O}$. 
The differences in bond lengths might be due to different possible resonating structures of ligand. According to our data the probability of the two resonance forms ' $a$ ' and 'b', (Fig. 8), (Charalambous et al., 1988), is high, participating in complex formation.

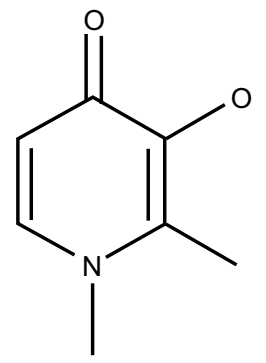

(a)

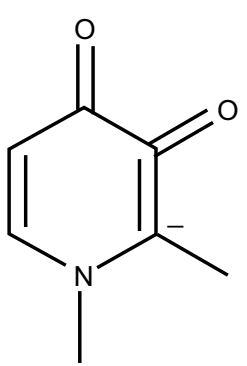

(b)
Fig. 8. The two possible resonance forms of deferiprone (a) and (b).

The presence of different numbers of water of crystallization might be the cause of difference in geometry of reported and studied crystal. The difference in bond length between two $\mathrm{C}-\mathrm{O}$ bonds $\Delta(\mathrm{C}-\mathrm{O})$ is $0.03 \AA$ that agrees with the assigned $\Delta(\mathrm{C}-\mathrm{O})$ value for 3-hydroxy4-pyridinonate complexes with +3 metal ions (Burgess and Rangel, 2008).

The slightly distorted octahedral fashion $\mathrm{O}(2)-\mathrm{Fe}-\mathrm{O}$ (1) angle $=94.6^{\circ}$; distorted octahedral configuration forming bonds with six oxygen atoms (two from each ligand) of the three ligands. The three ligand units show the corresponding bond lengths and angles, with hardly distinct $\mathrm{Fe}-\mathrm{O}$ ("keto") and $\mathrm{Fe}-\mathrm{O}$ ("hyroxy") lengths in the complex Fe (1)-O (1) and Fe (1)-O (2) distances $=2.02$ and $2.07 \AA$, respectively. The CCDC number for the crystal is 1895257 .

\section{Conclusion}

In the present study homo and mixed ligand complexes of $\mathrm{Fe}^{\text {(III) }}$ with deferiprone, an oral drug used for chelation therapy in iron overloaded thalassemic patients and Kojic acid, were prepared and characterized through different techniques. The mixed ligand complex of iron with both these types of ligands is a new complex and has not been reported before. This study may open a new window for improvement in chelation therapy for iron effective medicine with its minimal side effects.

Conflict of Interest. The authors declare no conflict of interest.

\section{References}

Burgess, J., Rangel, M. 2008. Hyroxypyranones, hydroxypyridinones and their complexes. In: Advances in Inorganic Chemistry, R. V. Eldik (eds.), vol. 60, pp. 167-229. $1^{\text {st }}$ edition, Elsevier, USA.

Charalambous, J., Dodd, A., McPartlin, M., Matondo, S.O.C., Pathirana, N.D., Harold, R.P. 1988. Synthesis and X-ray crystal structure of tris(1,2dimethyl-3-hydroxypyrid-4-onato)iron ${ }^{(I I I)}$. Communication, 7: 2235-2237.

Galanello, R., Origa, R. 2010. Beta-thalassemia. Orphanet Journal of Rare Disease, 5-11.

Jamuar, S.S., Lai, A.H.M. 2012. Safety and afficacy of iron chalation therapy with deferiprone in patients with transfusion dependant thalassemia. Therapeutic Advavances in Hematology, 3: 299307.

Nurchi, V.M., Crisponi, G., Lachowicz, J.I., Murgia, S., Pivetta, T., Antonio, R., Jaun, N., Josefa, M.G., Alicia, D., Alfonso, C., Zbigniew, S. 2010. Iron ${ }^{(I I I)}$ and aluminum ${ }^{(\mathrm{III})}$ complexes with hydroxypyrone ligands aimed to design kojic acid derivatives with new perspectives. Journal of Inorganic Biochemistry, 104: 560-569.

Nurchi, V.M., Crisponi, G., Pivetta, T., Donatoni, M., Remelli, M. 2008. Potentiometric, spectrophotometric and calorimetric study on iron ${ }^{(\mathrm{III})}$ and copper $^{\text {(II) }}$ complexes with 1,2-dimethyl-3-hydroxy4-pyridinone. Journal of Inorganic Biochemistry, 102: 684-692.

Piantavini, M.S., Gonçalvesa, Â.G., Trindadea, A.C.L.B., Noseda, M.D., Mercê, A.L.R., Machado, A.E.H., Pontarolo, R. 2017. Elucidation of the electronic spectrum changes of $\mathrm{KA}-\mathrm{Al}^{3+}$ complex by potentiometric titration, FTIR, 13C RMN and quantum mechanics. Quimca Nova, 40: 774-780.

Ragab, L.A., Hamdy, M.M., Shaheen, I.A., Yassin, R.N. 2013. Blood transfusion among thalassemia patients: A single Egyptian center experience. Asian Journal of Transfusion Sciences, 7: 33-36.

Saghaie, L., Hider, R. 2008. Synthesis and physic chemical properties of a series of bidentate 3hydroxypyridine-4-ones iron chelating agents. Research in Pharmceutical Sciences, 3: 21-30.

Santos, M.A., Chaves, S. 2015. 3-hydroxypyridinone derivatives as metal sequestering agents for therapeutic use. Future Medicinal Chemistry, 7: 383410. 